\title{
Disentangling the relative importance of species occurrence, abundance and intraspecific variability in community assembly: a trait-based approach at the whole-plant level in Mediterranean forests
}

\author{
Enrique G. de la Riva, Ignacio M. Pérez-Ramos, Ambra Tosto, Carmen M. Navarro-Fernández, \\ Manuel Olmo, Teodoro Marañón and Rafael Villar
}

E. G. de la Riva (enga70@gmail.com), A. Tosto, M. Olmo and R. Villar, Área de Ecología, Facultad de Ciencias, Univ. de Córdoba, ES-14071

Córdoba, Spain. - I. M. Pérez-Ramos, C. M. Navarro-Fernández and T. Marañón, Inst. de Recursos Naturales y Agrobiología de Sevilla, IRNAS, CSIC, ES-41012 Seville, Spain.

\begin{abstract}
Understanding which factors and rules govern the process of assembly in communities constitutes one of the main challenges of plant community ecology. The presence of certain functional strategies along broad environmental gradients can help to understand the patterns observed in community assembly and the filtering mechanisms that take place. We used a trait-based approach, quantifying variations in aboveground (leaf and stem) and belowground (root) functional traits along environmental gradients in Mediterranean forest communities (south Spain). We proposed a new practical method to quantify the relative importance of species turnover (distinguishing between species occurrence and abundance) versus intraspecific variation, which allowed us to better understand the assemblage rules of these plant communities along environmental gradients. Our results showed that the functional structure of the studied plant communities was highly determined by soil environment. Results from our modelling approach based on maximum likelihood estimators showed a predominant influence of soil water storage on most of the community functional traits. We found that changes in community functional structure along environmental gradients were mainly promoted by species turnover rather than by intraspecific variability. Specifically, our new method of variance decomposition demonstrated that between-site trait variation was the result of changes in species occurrence rather than in the abundance of certain dominant species. In conclusion, this study showed that water availability promoted the predominance of specific trait values (both in above and belowground fractions) associated to a resource acquisition or conservation strategy. In addition, we provided evidence that changes on community functional structure along the environmental gradient were mainly promoted by a process of species replacement, which represent a crucial step towards a more general understanding of the relative importance of intraspecific versus interspecific trait variation in these woody Mediterranean communities.
\end{abstract}

Understanding which factors and rules govern the process of species assembly in communities constitutes one of the main challenges of plant community ecology (Diamond 1975, Keddy 1992). To this end, the functional approach is a broadly-known key tool that emerged some years ago to better understand the mechanisms underlying community assembly along environmental gradients, as can be deduced from the large increase of published manuscripts on this specific issue (Lepš et al. 2011, Bernard-Verdier et al. 2012, Laliberté et al. 2012, Pérez-Ramos et al. 2012, Kichenin et al. 2013, Jung et al. 2014). Thus, the use of functional traits, i.e. 'morpho-physio-phenological attributes which have an indirect impact on fitness via their effects on growth, reproduction and survival' (Violle et al. 2007) is the base of numerous studies (trait-based) that scale-up from species to community level with the aim of attempting to explain the assembly rules of plant communities in diverse biomes (Violle et al. 2007, Shipley 2010, Garnier and Navas 2012). Most of these studies have focused on above-ground traits, mainly leaves (Ackerly et al. 2002, Bernard-Verdier et al. 2012, Domínguez et al. 2012, Spasojevic and Suding 2012, Kichenin et al. 2013) and stems (Cornwell and Ackerly 2009, Baraloto et al. 2010), probably due to the greater ease of their measurements compared with those of the belowground fraction (Holdaway et al. 2011). Thus, the role of root traits in the process of community assembly remains largely unexplored despite their recognized implications in plant-soil interactions and plant functional strategies (Silva and Rego 2003, Holdaway et al. 2011, McCormack et al. 2012). More insight will be thus gained from approaches including both the above and belowground fractions of plant communities. 
In Mediterranean ecosystems, strong environmental filters such as summer drought are expected to constrain the range of certain key functional traits of the community, selecting those species of the regional pool harbouring a set of attributes that enable them to persist in a particular site (Cornwell et al. 2006, Bernard-Verdier et al. 2012). In spite of the widely recognized importance of water availability as one of the main limiting resources for plants in Mediterranean ecosystems (Terradas 2001), recent studies in grassland communities have revealed a greater number of functional adaptations to soil nutrient scarcity than to drought (Ordoñez et al. 2009, Pérez-Ramos et al. 2012). Further trait-based studies are therefore essential to disentangle the relative importance of soil water and nutrient availability as drivers of plant community assembly in Mediterranean ecosystems, particularly for woody plant species.

Changes in community functional structure (i.e. trait composition at the community level) in response to environmental filters may be due to the turnover of species with different trait values (interspecific variation), to withinspecies changes in trait values (intraspecific variability) or to both processes acting simultaneously (Garnier et al. 2004, Albert et al. 2010a). In turn, interspecific variation can be decomposed into two different components of species turnover (Jung et al. 2014) due to changes in species occurrence (qualitative component) or species abundance (quantitative component). The quantification of these two components of species turnover may be relevant for determining which ecological processes are governing the rules of community assembly (Cingolani et al. 2007). On the one hand, changes in species occurrence seem to be associated with habitat filtering, either as a result of abiotic factors which imposes strong constraints on local trait distributions selecting only those species with suitable traits for limiting abiotic conditions (Keddy 1992, Cleland et al. 2011) or as a result of superior competitors which could promote disproportionally large effect on local resources, acting as abiotic constraints (Chesson 2000, Gross et al. 2013). On the other hand, changes in species abundance seem to result mainly from biotic interactions (facilitation or competition), which promote trait dissimilarity resulting from niche differentiation and allow coexistence by decreasing competition (MacArthur and Levins 1967, Stubb and Wilson 2004, Gross et al. 2009, Bernard-Verdier et al. 2012, Siefert 2012). However, to our knowledge, how species occurrence and abundance contribute to changes in community trait composition has not been partitioned yet along environmental gradients. To disentangle both sources of variability, we propose here a practical and simple method (modified from Lepš et al. 2011) to quantify the relative importance of species occurrence versus species abundance on changes in community functional structure, which will contribute for a better understanding of community assembly rules under particular environmental constraints.

In this study, our main objective was to discern which abiotic factors and mechanisms govern the process of community assembly along broad environmental gradients in Mediterranean forests of southern Spain. To accomplish this goal, we used a trait-based approach quantifying both aboveground (leaf and stem) and belowground (root) functional traits related to resource acquisition and plant structure. First, we identified which environmental drivers were best associated with functional trait variation and species distribution at the community level along a local environmental gradient. Second, we applied a new method to quantify the relative importance of species turnover (disentangling between species occurrence and abundance) versus intraspecific variation as mechanisms underlying changes in community functional structure along the explored environmental gradients.

\section{Material and methods}

\section{Study area}

The Mediterranean forests studied are located in Sierra Morena mountains, in the south of Spain (Córdoba). The area is characterized by a continental-Mediterranean climate with cold, wet winters and dry, warm summers. Mean annual temperature is $17.6^{\circ} \mathrm{C}$ (with maximum values in summer reaching $40^{\circ} \mathrm{C}$ ) and mean annual precipitation is $536 \mathrm{~mm}$ (with a three-month period in summer without rainfall; data from AEMET for the years 1971-2000). Bedrock is formed by siliceous substratum, which produces neutral or slightly acid soils (Leptosols). Shrub species such as Cistus albidus, Genista hirsuta, Quercus coccifera and Rosmarinus officinalis are abundant on upper slopes and hilltops, while broadleaf deciduous trees such as Alnus glutinosa, Celtis australis, Fraxinus angustifolia and Ulmus minor are dominant in valley bottoms (Supplementary material Appendix 1 Table A1-A2).

\section{Sampling design}

Nine sampling sites distributed over three different southfacing slopes (with at least $10 \mathrm{~km}$ of separation between them, and no climatic differences between them, Supplementary material Appendix 1 Table A3) were selected along a topographic gradient (from ridges to valley bottoms) with the aim of spanning a broad range of variations in soil resource availability (Supplementary material Appendix 1). Four $20 \mathrm{~m}$-long transects in each sampling site were randomly set up, perpendicular to the slope and parallel among them, with a minimum distance of $10 \mathrm{~m}$ relative to one another. In the spring of 2012, species abundance and composition were determined measuring the cover of each woody species intercepted by each of the four $20 \mathrm{~m}$ lines (total abundance can exceed $20 \mathrm{~m}$ since the overlapping vegetation layers were taken into account). The mean relative abundance for each species and site was calculated as the mean value of the four transects. For trait measurements, we ranked them by their relative abundances and selected those species representing at least the $90 \%$ of the total plant woody abundance measured in each site. This resulted in a total of 38 different sampled species, many of them appearing in more than one sampling site (Supplementary material Appendix 1 Table A2).

\section{Characterization of the environment}

Different soil characteristics were measured in each of the nine sampling sites. In May 2012, two soil samples per transect were taken using an auger up to a maximum depth of one meter. These soil samples were collected within a 
short period of time (three consecutive days) to avoid possible differences among sites derived from weather. Soil water content was quantified by the gravimetric method, i.e. weighing fresh soil samples and re-weighing them after being oven-dried at $100^{\circ} \mathrm{C}$ for $48 \mathrm{~h}$. From these measurements, we calculated an integrative variable of the whole soil profile for each of the 36 transects (soil water storage, SWS) as: (fresh soil mass - dry soil mass)/ area of the auger section $\left(5 \mathrm{~cm}^{2}\right)$.

Two additional soil samples of the top $20 \mathrm{~cm}$ of depth (where nutrient uptake mostly occurs; Jobbágy and Jackson 2001) were collected in each transect and further mixed to make a combined soil sample per transect, using this for physico-chemical analysis. In the laboratory, samples were air-dried, crushed and sieved; the fraction of less than $2 \mathrm{~mm}$ was analyzed using standard soil methods (Sparks 1996). The $\mathrm{pH}$ was measured in a 1:2.5 soil: water suspension; soil organic matter was determined by Walkley and Black method and total $\mathrm{N}$ was determined by Kjeldahl digestion. Available $\mathrm{P}$ was estimated by Olsen method; $\mathrm{Ca}, \mathrm{K}$ and $\mathrm{Mg}$ were extracted with $1 \mathrm{M}$ ammonium acetate and determined by atomic absorption spectrophotometry.

\section{Plant measurements}

Nine above-ground and two below-ground functional traits related to morphology, physiology and chemical composition were measured in each of the dominant species (Table 1), due to their suggested importance in the process of community assembly (Garnier et al. 2004, Shipley et al. 2006, Violle et al. 2007, Carlucci et al. 2012, Garnier and Navas 2012, Pérez-Ramos et al. 2012). In late spring 2012, during the maximum peak of plant growth, healthy adults for each of the dominant species of each site were randomly selected for measuring leaf, stem, root and whole-plant traits. All trait measurements were carried out according to the criteria defined by Cornelissen et al. (2003). For a detailed protocol of sample harvesting and trait measurements see Supplementary material Appendix 2.

\section{Above-ground functional traits}

Plant height $(\mathrm{m})$ and cover (canopy projection; $\mathrm{m}^{2}$ ) of ten individuals per species and site were measured (in total 750 individuals). Leaf and stem traits, such as specific leaf area (SLA; leaf area per unit of dry leaf mass; $\mathrm{m}^{2} \mathrm{~kg}^{-1}$ ), leaf dry matter content (LDMC; dry mass per unit of water-saturated fresh mass; $\mathrm{mg} \mathrm{g}^{-1}$ ), leaf nitrogen concentration (LNC; $\mathrm{mg} \mathrm{g}^{-1}$ ), leaf size $\left(\mathrm{cm}^{2}\right)$, leaf chlorophyll (LChl; concentration of chlorophyll per unit of fresh leaf mass; $\mu \mathrm{g} \mathrm{g}^{-1}$ ) and stem dry matter content (SDMC; dry mass per unit of water-saturated fresh mass; $\mathrm{mg}^{-1}$ ) were measured in six individuals per species and site (in total 450 individuals). For leaf measurements, a variable number (depending on the averaged leaf size of each species) of newly matured leaves were sampled in stems or twigs from the sun-exposed part of the canopy.

A mixture of the same amount of leaves from six different individuals per species and site were collected for measuring one trait directly related to water use efficiency: carbon isotopic ratio $\left(\delta^{13} \mathrm{C} ; \%\right.$, Farquhar et al. 1982$)$.

\section{Below-ground functional traits}

Roots were sampled at the individual level by excavating the first $20-30 \mathrm{~cm}$ of soil depth near the plant basal stem, ensuring thus that the sampling roots belonged to the selected individual. The roots of four individuals per species and site (in total 300 individuals) were sampled. We selected this specific soil depth based on other studies in Mediterranean woody vegetation (Silva and Rego 2004) that demonstrated that the largest fraction of fine roots appears in the first $27 \mathrm{~cm}$ of soil depth. These root samples were used to measure two belowground traits on fine roots $(<2 \mathrm{~mm}$ in diameter) related to water and nutrient uptake (Jackson et al. 1997): specific root length (SRL, root length per unit of dry root mass; $\mathrm{m} \mathrm{kg}^{-1}$ ) and root dry matter content (RDMC, root dry mass per unit of root fresh mass; $\mathrm{mg} \mathrm{g}^{-1}$ ). These data were obtained by analyzing the scanned root samples with WinRHIZO 2009 and weighing the dry root mass (for more details see Supplementary material Appendix 2).

Table 1. Mean standard deviation and range of the 11 community functional traits considered in this study. Abbreviations have also been indicated when necessary.

\begin{tabular}{|c|c|c|c|c|c|}
\hline Trait & Abbreviation & Unit & Mean & Standard deviation & Range \\
\hline \multicolumn{6}{|l|}{ Whole-plant traits } \\
\hline Plant height & & $\mathrm{m}$ & 4.30 & 2.32 & $1.92-7.81$ \\
\hline Plant cover & & $m^{2}$ & 20.07 & 16.54 & $3.53-52.52$ \\
\hline \multicolumn{6}{|l|}{ Leaf traits } \\
\hline Leaf size & & $\mathrm{cm}^{2}$ & 11.51 & 12.19 & $2.72-39.66$ \\
\hline Leaf dry matter content & LDMC & $\mathrm{mg} \mathrm{g}^{-1}$ & 415.3 & 65.89 & $295.9-496.5$ \\
\hline Specific leaf area & SLA & $\mathrm{m}^{2} \mathrm{~kg}^{-1}$ & 11.55 & 6.46 & $6.03-24.58$ \\
\hline Leaf nitrogen concentration & LNC & $\%$ & 2.08 & 0.53 & $1.50-3.16$ \\
\hline Leaf chlorophyll ${ }^{1}$ & LChl & $\mu \mathrm{g} \mathrm{g}^{-1}$ & 1566.2 & 782.8 & $675.9-2875.5$ \\
\hline$\delta^{13} \mathrm{C}$ & & $\%$ & -28.2 & 1.22 & $(-29.82)-(-26.34)$ \\
\hline \multicolumn{6}{|l|}{ Stem traits } \\
\hline Stem dry matter content & SDMC & $\mathrm{mg} \mathrm{g}^{-1}$ & 485.0 & 49.4 & $416.8-585.9$ \\
\hline \multicolumn{6}{|l|}{ Root traits } \\
\hline Root dry matter content & RDMC & $\mathrm{mg} \mathrm{g}^{-1}$ & 354.5 & 66.4 & $227.5-421.1$ \\
\hline Specific root length & SRL & $\mathrm{mg}^{2} \mathrm{~g}^{-1}$ & 13.31 & 5.12 & 7.99-21.94 \\
\hline
\end{tabular}

Based on fresh mass. 


\section{Data analyses}

\section{Community weighted means}

To scale up from species to community level, all these traits (both aboveground and belowground) were weighted by the relative abundance of each species to calculate community weighted means (CWM), according to Garnier et al. (2004). The CWM traits were calculated for each site as $\sum \mathrm{P}_{\mathrm{i}} \times$ Trait $_{\mathrm{i}}$, where $P_{i}$ is the relative abundance of the species ' $I$ ' in this site, and Trait ${ }_{\mathrm{i}}$ is the average trait value obtained for the species ' $\mathrm{I}$ ' in the same site (Supplementary material Appendix 3).

\section{Relationships among environmental factors}

To understand the multidimensional relationships between the eight environmental factors considered in this study (Table 2), we conducted a principal component analysis (PCA) based on a correlation matrix of the eight variables in the nine sampling sites. The abiotic environment of each site was characterized by using averaged values of the four transects. Pearson's correlation analyses were also conducted to explore the level of dependence between these environmental variables, preceded by a Kolmogorov-Smirnov test in order to check the normality of the distribution of the studied abiotic variables. To test independence between zones and slopes, a one-way ANOVA was carried out, followed by post hoc multiple pairwise comparisons (Tukey's test) with the non-correlated variables. All these analyses were carried out using SPSS 15.0.

\section{Environmental filters as drivers of species distribution and community functional trait structure}

In order to investigate how species segregate along the studied environmental gradients, we used the redundancy analysis (RDA; implemented in the package 'vegan'; Oksanen et al. 2007). The significant relationship between species abundance and the non-correlated environmental factors (SWS, $\mathrm{pH}, \mathrm{N}, \mathrm{P}$ and $\mathrm{Mg}$ ) were tested using the permutational multivariate analysis of variance (PERMANOVA, Anderson 2001).

To determine which abiotic factors were best associated with community trait variation, we conducted maximum likelihood techniques using the likelihood package ver. 1.1 for R in R 2.10.0 statistical platform (<www.r-project.org >). From the initial eight environmental variables, we only chose for analyses a subset of five independent factors (including SWS, $\mathrm{pH}, \mathrm{N}, \mathrm{P}$ and $\mathrm{Mg}$ ), after discarding those that were significantly correlated with at least one of the selected variables (Ca, K and OM, Supplementary material Appendix 4 Table A1). We tested three alternative functions that encompass different responses of communities to abiotic factors: a linear response (linear model), an exponential response (exponential model) and a saturating response (Michaelis-Menten model). We first tested models for each environmental factor (SWS, $\mathrm{pH}, \mathrm{N}, \mathrm{P}$ and $\mathrm{Mg}$ ) and function independently, and the best of the three models was compared with the null model, which assumes no effect of any factor. Second, to test for amongfactors interactions, we fitted two-factor models using those environmental factors that had an effect on the different functional parameters when evaluated independently. We tried alternative models in which the second environmental factor was added either additively or multiplicatively. Models were parameterized with maximum likelihood (Edwards 1992), using a simulating annealing algorithm. Competing models to predict functional parameters were selected with the Akaike information criterion corrected for small sample sizes (AICc) (Burnham and Anderson 2002).

\section{Disentangling the relative importance of species turnover (species occurrence versus abundance) and intraspecific variability}

To determine the relative importance of species occurrence, abundance and intraspecific variability as mechanisms underlying changes in community functional trait structure, we used a new method (modified from Lepš et al. 2011). First, we calculated the three types of CWM parameters proposed by Lepš et al. (2011): 1) 'specific' average traits, using trait values of each species within each site, whose variation can be caused by both species turnover and intraspecific trait variability; 2) 'fixed' trait values, using mean trait values of each species along the whole environmental gradient (i.e. site-independent trait values), whose variation is only due to changes in species turnover; and 3) 'intraspecific variabilitity' trait values, which are calculated from the differences between 'specific' and 'fixed' average traits and permit an estimation of the pure effects of the intraspecific variability:

intraspecific variability parameter $=$ specific parameter fixed parameter

Second, we computed two new community parameters with the aim of disentangling the effects of the two components of species turnover (species occurrence and species abundance): 1) 'unweighted' trait values, which were calculated similarly to the above-mentioned 'fixed' trait values but without weighting them by their relative species abundances; and 2) 'species-abundance' trait values, calculated from differences between 'fixed and 'unweighted' trait values. Thus, variation in the 'unweighted' trait values is solely affected by

Table 2. Mean, standard deviation and range of the eight environmental variables quantified in the soil of the nine studied sampling sites.

\begin{tabular}{lccccc}
\hline Variables & Abbreviation & Unit & Mean & Standard deviation & Range (min-max) \\
\hline Soil water storage & $\mathrm{SWS}$ & $\mathrm{I} \mathrm{m}^{-2}$ & 59.94 & 23.13 & $25.60-93.62$ \\
$\mathrm{pH}$ & $\mathrm{pH}$ & & 6.86 & 0.47 & $6.25-7.83$ \\
Total nitrogen & $\mathrm{N}$ & $\%$ & 0.14 & 0.04 & $0.08-0.19$ \\
Available phosphorus & $\mathrm{P}$ & $\mathrm{mg} \mathrm{kg}^{-1}$ & 4.24 & 3.89 & $1.07-12.02$ \\
Available potassium & $\mathrm{K}$ & $\mathrm{mg} \mathrm{kg}^{-1}$ & 145.0 & 50.13 & $71.5-228.5$ \\
Available calcium & $\mathrm{Ca}$ & $\mathrm{mg} \mathrm{kg}^{-1}$ & 2677.3 & 1287.3 & $1395.5-5272.5$ \\
Available magnesium & $\mathrm{Mg}$ & $\mathrm{mg} \mathrm{kg}^{-1}$ & 347.8 & 152.7 & $193.7-519.2$ \\
Organic matter & $\mathrm{OM}$ & $\%$ & 3.63 & 0.97 & $2.06-4.75$ \\
\hline
\end{tabular}


changes in species occurrence (presence/absence of species) whereas variation in 'species-abundance' trait values allows us to estimate the pure effects of changes in species abundance as follows:

species abundance parameter $=$ fixed parameter ('species turnover') - unweighted parameter ('species occurrence')

Finally, we explored 'CWM trait - environment' linkages for the two new types of community parameters ('unweighted and 'species-abundance' trait values) as well as for that used to estimate the pure effects of the intraspecific variability ('intraspecific variability' trait values). To quantify how much variability is accounted for each individual component (species occurrence, abundance and intraspecific variability), we used the method based on the sum of squares (SS) decomposition (details in Lepš et al. 2011), using the best likelihood models previously. Since the effects of the aboveexplained community parameters do not always vary independently, we also considered the effect of their covariation. In turn, covariation was partitioned into two different components, as specified in the following equations:

$\operatorname{covSS} S_{I}=S S_{\text {specific }}-S S_{\text {fixed }}-S S_{\text {intraspecific variability }}$ $\operatorname{covSS}_{\text {II }}=S S_{\text {fixed }}-S_{\text {species occurrence }}-S_{\text {species abundance }}$

where covSS $S_{I}$ is the covariation between species turnover and intraspecific variation and covSS $\mathrm{II}_{\text {II }}$ represents the covariation between species occurrence and abundance.

In summary, the maximum variability included in 'specific' average traits (i.e. that due to changes in species occurrence, abundance and intraspecific trait variability) can be defined as:

$$
\begin{aligned}
S S_{\text {specific }}= & S S_{\text {species occurrence }}+S_{\text {species abundance }} \\
& +S S_{\text {intraspecific variability }}+\operatorname{cov} S S_{I}+\operatorname{covSS}_{\text {II }}
\end{aligned}
$$

For more details see supporting information (Supplementary material Appendix 3).

Data available from the Dryad Digital Repository: $<$ http://dx.doi.org/10.5061/dryad.dr275> (de la Riva et al. 2015).

\section{Results}

\section{Environmental factors}

We detected a large variability between sites in the abiotic environment, with high differences in soil water storage (SWS) and soil nutrient concentration (Table 2, Fig. 1). No significant relationship was found between SWS and the concentration of any of the soil nutrients quantified in this study (Supplementary material Appendix 4 Table A1). Results from the PCA analysis showed a set of environmental factors related to soil fertility $(\mathrm{N}, \mathrm{K}, \mathrm{Ca}, \mathrm{Mg}$ and organic matter), which exhibited the highest scores in the first principal component (explaining the $49 \%$ of the total variance; Fig. 1). The second principal component (explaining 33\% of the variance) was mainly defined by SWS, $\mathrm{P}, \mathrm{pH}$ and $\mathrm{Ca}$ in the negative extreme of the axis (Fig. 1). No statistical differences between zones were found for any of the

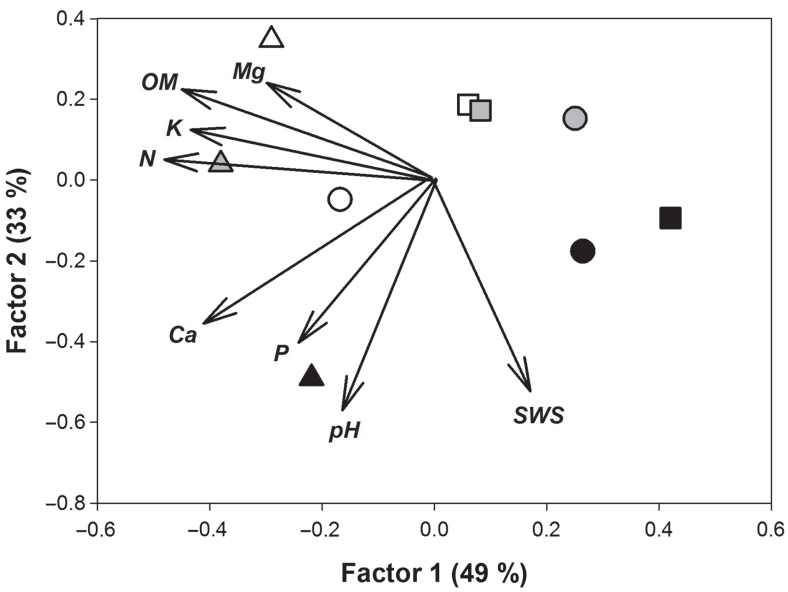

Figure 1. Ordination of the eight environmental variables considered in this study (abbreviations in Table 2) and the nine sampling sites in the space defined by the two first axes of the principal component analysis. The three study zones are separated by symbols: circles (VL), triangles (BP), and squares (LT), and the slope position by color: upper in white, medium in gray and lower in black; see complete names in Supplementary material Appendix 1.

environmental variables. However, soil water storage significantly differed as a function of the slope, with plots located in valley bottoms exhibiting higher values of SWS compared with the rest $(\mathrm{p}=0.01$; Supplementary material Appendix 4 Table A2).

\section{Environmental filters as drivers of species distribution and community functional trait structure}

Along the first RDA axis (explaining the $34 \%$ of the total variance; Fig. 2), we detected strong variations in species composition from forests dominated by deciduous tree species such as Fraxinus angustifolia, Salix atrocinerea or Ulmus minor to scrublands dominated by evergreen and

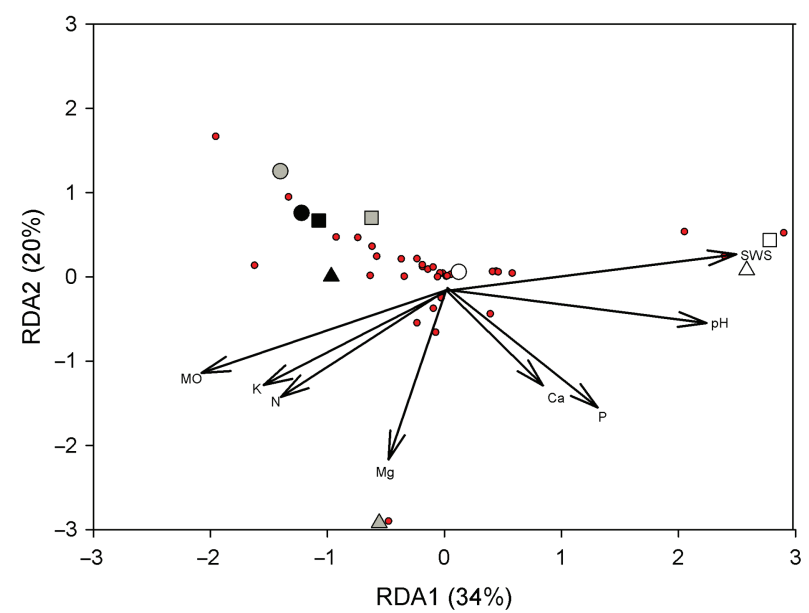

Figure 2. Ordination diagrams on the first two axes of redundancy analysis, eight environmental variables (abbreviations in Table 2), nine sites and 38 woody species. The three study zones are separated by symbols: circles (VL), triangles (BP), and squares (LT), and the slope position by color: upper in black, medium in gray and lower in white; see complete names in Supplementary material Appendix 1. 
sclerophyllous arborescent shrubs such as Arbutus unedo, Quercus ilex and Rosmarinus officinalis. Soil water storage was the only significant predictor for this floristic distribution $(\mathrm{p}<0.05$; Supplementary material Appendix 5 Table A1), as indicated by the results from the permutational multivariate analysis of variance (PERMANOVA).

Our results showed that the functional structure of the studied plant communities was highly determined by soil water storage. Thus, results from our modelling approach showed a predominant influence of soil water storage on most of the functional traits considered in this study (being selected as the best abiotic predictor for six out of the 11 analyzed traits) (Table 3). Communities growing in moister soils showed higher values of plant size (i.e. height and cover), leaf chlorophyll, specific leaf area and specific root length, all of them related to a rapid resource-uptake strategy. In contrast, drier conditions promoted the predominance of communities with higher values of $\delta^{13} \mathrm{C}$ (Table 3), reflecting a more efficient use of water under water-limited conditions. In addition, soil $\mathrm{pH}$ also played an important role in some of the functional traits considered in this study, being positively related to leaf size (Table 3). In contrast, soil nutrient availability did not have any significant role in community trait variation (Table 3 ).

When analogous CWM traits for leaves and roots were compared, we found similar trends along the range of the main environmental factors. As an example, soil water storage (SWS) influenced positively the ratio acquisition/investment for both leaves $\left(\mathrm{SLA}_{\mathrm{CWM}}\right)$ and roots $\left(\mathrm{SRL}_{\mathrm{CWM}}\right)$ of plant communities (Fig. 3).

\section{Species occurrence, abundance and intraspecific variability}

Results from partitioning the total variability in each of the functional traits considered in this study (belonging either to the aboveground or the belowground fractions) demonstrated that changes in community functional structure along environmental gradients were mainly promoted by species turnover (Fig. 4). In contrast, intraspecific variability implied very little variation in these community functional traits. Interestingly, our new method for disentangling species turnover into its quantitative and qualitative components enabled us to demonstrate that between-site trait variation was the result of changes in species occurrence rather than in the abundance of certain dominant species. The total variation was increased by a positive covariation between species turnover and intraspecific variability, as well as between species occurrence and abundance (except leaf size $_{\mathrm{CWM}}$, where the covariation II was highly negative) (Fig. 4).

\section{Discussion}

\section{Environmental drivers of community functional structure}

We found a large variation in the functional traits considered in this study along the explored environmental gradients, which suggest a non-random trait distribution at the community level (Weiher and Keddy 1999, Stubbs and Wilson 2004, Cornwell and Ackerly 2009, Freschet et al. 2011, de Bello et al. 2013). This means that only a particular set of trait values is advantageous under certain environmental conditions, thus limiting the range of trait space that species and communities are able to occupy (Díaz et al. 1998, Holdaway and Sparrow 2006, Cornwell and Ackerly 2009, de la Riva et al. 2011).

Our results showed that community functional traits were mainly driven by soil water storage. In contrast, soil nutrient availability did not (apparently) exert any significant

Table 3. Summary of the best-fitted models analyzing trait values (at the community level) in response to soil factors. The best-supported models $(\triangle \mathrm{AIC} \leq 2)$ have been highlighted with bold letters. See Table 1 and 2 for abbreviations of traits and soil factors. FF: form of function (LIN: linear function).

\begin{tabular}{|c|c|c|c|c|c|c|c|}
\hline & Dependent variable & Soil factors & FF & Relation & $\mathrm{R}^{2}$ & $\mathrm{AIC}$ & $\triangle \mathrm{AIC}$ \\
\hline \multirow[t]{4}{*}{ Whole-plant traits } & Plant height & SWS & LIN & + & 0.75 & 37.96 & 0.00 \\
\hline & & & null & & & 45.61 & 7.65 \\
\hline & Plant cover & SWS & LIN & + & 0.60 & 77.44 & 0.00 \\
\hline & & & null & & & 80.99 & 3.55 \\
\hline \multirow{14}{*}{ Leaf traits } & Leaf size & pH & LIN & + & 0.61 & 71.81 & 0.00 \\
\hline & & SWS & LIN & + & 0.56 & 72.87 & 1.06 \\
\hline & & & null & & & 75.50 & 3.69 \\
\hline & LDMC & & null & & & 22.58 & 0.00 \\
\hline & SLA & SWS & LIN & + & 0.70 & 57.90 & 0.00 \\
\hline & & $\mathrm{pH}$ & LIN & + & 0.54 & 61.92 & 4.02 \\
\hline & & & null & & & 64.06 & 6.16 \\
\hline & LNC & & null & & & 24.79 & 0.00 \\
\hline & LChl & SWS & LIN & + & 0.71 & 143.86 & 0.00 \\
\hline & & & null & & & 150.15 & 6.30 \\
\hline & $\delta^{13} \mathrm{C}$ & SWS & LIN & - & 0.71 & 30.76 & 0.00 \\
\hline & & $\mathrm{pH}$ & LIN & - & 0.13 & 37.66 & 6.89 \\
\hline & & $P$ & LIN & - & 0.11 & 37.90 & 7.14 \\
\hline & & & null & & & 91.66 & 60.90 \\
\hline Stem traits & SDMC & & null & & & 22.56 & 0.00 \\
\hline \multirow[t]{3}{*}{ Root traits } & RDMC & & null & & & 106.00 & 0.00 \\
\hline & SRL & SWS & LIN & + & 0.53 & 57.90 & 0.00 \\
\hline & & & null & & & 59.89 & 2.00 \\
\hline
\end{tabular}




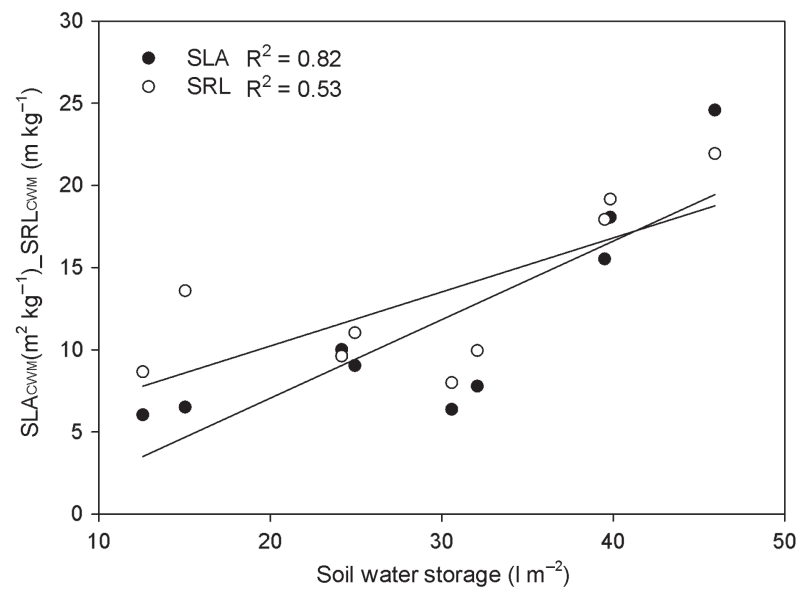

Figure 3. Relationships between analogous leaf and root community functional traits and the best-supported environmental predictor (SWS, soil water storage). The value of $\mathrm{R}^{2}$ has been also indicated. See Table 1 for trait abbreviations.

role or this was secondary compared with that of water. These results are in accordance with a previous study with Mediterranean woody plant species (Cornwell and Ackerly 2009), but contrast with others where soil nutrients played a predominant role as drivers of changes in community functional structure (Ordońez et al. 2009, Fyllas et al. 2009, Pérez-Ramos et al. 2012). These controversial results suggest that the relative importance of both types of soil resources for plant community assembly is likely to be influenced by several factors, including the ecosystem type, the range of variation of the explored environmental gradients, the scale of the studied system (landscape versus local) or the selected set of functional traits considered in the study.

Soil water availability mainly shaped the functional trait structure of the studied plant communities according to the widely known tradeoff between resource acquisition and

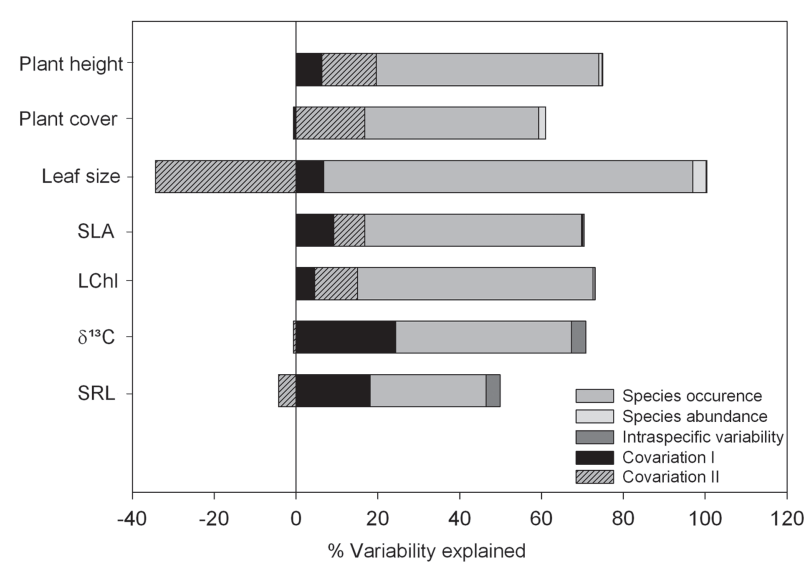

Figure 4. Partitioning of the total variability in the studied community functional traits along the best-supported environmental variables (Table 3 ). When the sum of the amount of variability explained by turnover and intraspecific variability effects is lower than that explained by the total variability of the community, covariation I reaches negative values. Similarly, negative values of covariation II appear when the sum of species occurrence and abundance effects is lower than that of species turnover. Functional traits have been abbreviated as indicated in Table 1 . conservation (Chapin et al. 1993, Grime 2001, Wright et al. 2004). Interestingly, both the aboveground and the belowground traits considered in this study showed a similar trend along the gradient of soil water storage, suggesting that a filtering process is operating for an integrated resourceuptake strategy at the community level (concept of plant community economics spectrum, sensu Pérez-Ramos et al. 2012). Communities growing in wetter sites exhibited higher values of SLA and SRL, which could potentially confer them with an advantage in resource-uptake efficiency by increasing the absorption surface per unit of tissue biomass (Reich et al. 1992, Ryser 1998). However, communities with higher values of SLA and SRL may be more vulnerable to drought conditions (Fitter 1987, Reich et al. 1991, 1998, Pérez-Ramos et al. 2013). Thus, water limitation could act as an abiotic filter, excluding or reducing the dominance of fast-growing species which are usually less tolerant to these more stressed conditions (Lopez-Iglesias et al. 2014).

In contrast, water shortage promoted the prevalence of communities with higher water-use efficiency (i.e. high values of $\delta^{13} \mathrm{C}$ ), which is commonly associated with a conservative water use strategy at the expense of slower plant growth (Farquhar et al. 1982, Domínguez et al. 2012). These slower-growth, drought-tolerant and more conservative species were probably excluded from wetter sites by a strong aboveground competition for space and light in the dense shade created by the tall trees and shrubs typical of these more productive sites.

\section{Disentangling the relative importance of species occurrence, abundance and intraspecific variability}

Our results from analyses of variance decomposition showed that variations in community functional traits along environmental gradients were mainly explained by changes in species turnover rather than being due to a strong intraspecific variability. Previous studies found similar patterns, though in general with higher values of intraspecific variability (Albert et al. 2010b, Jung 2010, de Bello et al. 2011, Pérez-Ramos et al. 2012, Jung et al. 2014). In this study, the proportion of variance explained by intraspecific variability was very low (below 5\%), in accordance with other Mediterranean studies focusing on aboveground traits (Roche et al. 2004, Cornwell and Ackerly 2009), which support the general agreement that trait variation is much greater among species than therein (Garnier et al. 2001). The low proportion of variance explained by intraspecific variability is also reflected in the low number of species that coincided in the different sampling sites (only 17 of 38 species appeared in more than one site), which reveals the predominance of a process of species replacement along the environmental gradient. In our study area, plant communities inhabiting water-limited habitats were predominantly composed of drought-tolerant evergreen species (i.e. Arbutus unedo, Quercus ilex, Rosmarinus officinalis), whereas plant communities growing in moister sites were dominated by deciduous species (i.e. Alnus glutinosa, Fraxinus angustifolia, Salix atrocinerea and Ulmus minor). Our results supports previous studies with Mediterranean woody plant communities (Cornwell and Ackerly 2009), but contrast with others that detected a strong relative importance of intraspecific variability as driver of changes in SLA (Jung 
et al. 2010, Auger and Shipley 2013, Kichenin et al. 2013). These contrasting results suggest that the relative contribution of intraspecific versus interspecific variability can differ largely among different spatial scales, species, traits and habitats of study (Albert et al. 2011, Auger and Shipley 2013, Carlucci et al. 2015).

Results from our method of total variability decomposition in three individual components (species occurrence, abundance and intraspecific variability) are novel for different reasons. First, to our knowledge, this is the first study that quantifies the relative importance of the two main sources of variability (species turnover vs. intraspecific variability) in belowground traits, particularly in woody plant species. Most previous studies have focused on aboveground traits (particularly leaves), whereas the variability included in those pertaining to the belowground component has remained largely unexplored. In this study, we have provided some light on this subject, showing that roots followed a similar pattern to leaves, with a lower percentage of variance explained by intraspecific variability (below 4\%) compared to that of species turnover. Further studies in other plant communities and systems are therefore necessary to discern whether these trends for the belowground fraction are consistent at a wider spatial scale.

Second, we have proposed a new method for disentangling the relative importance of species occurrence and abundance as components of species turnover, which could be potentially applied for answering different ecological questions. Using this new approach, we observed that variation in community functional structure along environmental gradients was not determined by changes in species abundance (with a percentage of explained variance below $5 \%$ for all the traits considered in this study) but by shifts in species occurrence. The higher relative importance of species occurrence suggests that the assembly mechanisms of these Mediterranean woody plant communities are the result of a process of habitat filtering which prevents the establishment of species with less suitable trait values for coping with environmental constraints (in our case water shortage). In contrast, in wetter soils, communities are predominantly dominated by acquisitive fast-growing species, which outcompete those associated with a more conservative strategy (Chesson 2000, Suding et al. 2005, Cornwell et al. 2006, Mayfield and Levine 2010, Weiher et al. 2011, Gross et al. 2013). Therefore, changes in climate conditions, such as the increased aridity predicted by climate change models (IPCC 2001), could cause a strong alteration in species composition of these communities (promoting the disappearance of species with acquisitive strategies) since abiotic filters act primarily on species occurrence rather than modifying their respective abundance values. The decomposition method of interspecific trait variation into its qualitative and quantitative components could be used as a valuable tool for a better understanding of community responses to environmental gradients due to changes in species occurrence and/or abundance (Ackerly and Cornwell 2007, Sandel et al. 2010). This approach could be also applied to a broad number of ecological contexts, such as those derived from global change predictions (McGill et al. 2006), which could allow gaining valuable insights into the relative importance of the different components of species turnover as drivers of the process of community assembly under changing environments.

\section{Conclusions}

In this study, we tried to discern the assemblage patterns of Mediterranean woody plant communities along natural environmental gradients, using a whole-level, trait-based approach. We found that soil water availability was the main abiotic driver of community functional structure, water-limited conditions promoting the predominance of specific trait values (both in above and belowground fractions) associated to a resource-acquisition or conservation strategy. Interestingly, the new method of variance decomposition that we proposed in this study enabled us to demonstrate that community functional structure was mainly promoted by a process of species replacement, while changes in species abundance and intraspecific variability were of lower importance for community assembly in these Mediterranean ecosystems. These findings represent a crucial step towards a more general understanding of the relative importance of intraspecific versus interspecific trait variation in plant communities, with strong implications for understanding the rules and mechanisms governing the process of community assembly along environmental gradients. Although our approach does not allow us to entirely disentangle the underlying mechanisms that drive the process of community assembly, it does provide a set of exciting hypotheses to be further investigated not only in Mediterranean but in other plant communities world-wide.

Acknowledgements - This study was funded by the Spanish MEC coordinated project DIVERBOS (CGL2011-30285-C02-01 and C02-02), the Andalusian ANASINQUE project (PGC2010RNM-5782), and European FEDER funds. Isotopic analysis was carried out in the LIE of EBD, CSIC, multielemental analysis of soil and plant samples in the IRNAS Analysis Service and N and C of leaves in the SCAI of University of Córdoba.

\section{References}

Ackerly, D. D. et al. 2002. Leaf size, specific leaf area and microhabitat distribution of chaparral woody plants: contrasting patterns in species level and community level analyses. - Oecologia 130: 449-457.

Ackerly, D. D. and Cornwell, W. K. 2007. A trait-based approach to community assembly: partitioning of species trait values into within- and among-community components. - Ecol. Lett. 10: 135-145.

Albert, C. H. et al. 2010a. A multi-trait a pproach reveals the structure and the relative importance of intra- vs interspecific variability in plant traits. - Funct. Ecol. 24: 1192-1201.

Albert, C. H. et al. 2010b. Intraspecific functional variability: extent, structure and sources of variation. - J. Ecol. 98: 604-613.

Albert, C. H. et al. 2011. When and how should intraspecific variability be considered in trait-based plant ecology? - Persp. Plant Ecol. Evol. Syst. 13: 217-225.

Anderson, M. J. 2001. A new method for non-parametric multivariate analysis of variance. - Aust. Ecol. 26: 32-46. 
Auger, S. and Shipley, B. 2013. Inter-specific and intra-specific trait variation along short environmental gradients in an old-growth temperate forest. - J. Veg. Sci. 24: 419-428.

Baraloto, C. et al. 2010. Decoupled leaf and stem economics in rain forest trees. - Ecol. Lett. 13: 1338-1347.

Bernard-Verdier, M. et al. 2012. Community assembly along a soil depth gradient: contrasting patterns of plant trait convergence and divergence in a Mediterranean rangeland. - J. Ecol. 100: 1422-1433.

Burnham, K. P. and Anderson, D. R. 2002. Model selection and multimodel inference: a practical information-theoretic approach, 2nd edn. - Springer.

Carlucci, M. B. et al. 2012. Individual-based trait analyses reveal assembly patterns in tree sapling communities. - J. Veg. Sci. 23: $176-186$.

Carlucci, M. B. et al. 2015. Between-and within-species trait variability and the assembly of sapling communities in forest patches. - J. Veg. Sci. 26: 21-31.

Chapin, F. S. III et al. 1993. Evolution of suites of traits in response to environmental stress. - Am. Nat. 142: 78-92.

Chesson, P. 2000. Mechanisms of maintenance of species diversity. - Annu. Rev. Ecol. Syst. 31: 343-366.

Cingolani, A. M. et al. 2007. Filtering processes in the assembly of plant communities: are species presence and abundance driven by the same traits? - J. Veg. Sci. 18: 911-920.

Cleland, E. E. et al. 2011. Patterns of trait convergence and divergence among native and exotic species in herbaceous plant communities are not modified by nitrogen enrichment. - J. Ecol. 99: 1327-1338.

Cornelissen, J. H. C. et al. 2003. A handbook of protocols for standardised and easy measurement of plant functional traits worldwide. - Aust J. Bot. 51: 335-380.

Cornwell, W. K. and Ackerly, D. D. 2009. Community assembly and shifts in plant trait distributions across an environmental gradient in coastal California. - Ecol. Monogr. 79: 109-126.

Cornwell, W. K. et al. 2006. A trait-based test for habitat filtering: convex hull volume. - Ecology 100: 1465-1471.

de Bello, F. et al. 2011. Quantifying the relevance of intraspecific trait variability for functional diversity. - Meth. Ecol. Evol. 2: 163-174.

de Bello, F. et al. 2013. Hierarchical effects of environmental filters on the functional structure of plant communities: a case study in the French Alps. - Ecography 36: 393-402.

de la Riva, E. G. et al. 2011. Rates of local colonization and extinction reveal different plant community assembly mechanisms on road verges in central Spain. - J. Veg. Sci. 22: 292-302.

de la Riva, E. G. et al. 2015. Data from: Disentangling the relative importance of species occurrence, abundance and intraspecific variability in community assembly: a trait-based approach at the whole-plant level in Mediterranean forests. - Dryad Digital Repository, < http://dx.doi.org/10.5061/dryad.dr275>.

Diamond, J. M. 1975. Assembly of species communities. - In: Cody, M. L. and Diamond, J. M. (eds), Ecology and evolution of communities. Belknap press, pp. 342-444.

Díaz, S. et al. 1998. Plant functional traits and environmental filters at a regional scale. - J. Veg. Sci. 9: 113-122.

Domínguez, M. T. et al. 2012. Relationships between leaf morphological traits, nutrient concentrations and isotopic signatures for Mediterranean woody plant species and communities. Plant Soil 357: 407-424.

Edwards, A. W. F. 1992. Likelihood, expanded edition. - Johns Hopkins Univ. Press.

Farquhar, G. D. et al. 1982. On the relationship between carbon isotope discrimination and the intercellular carbon dioxide concentration in leaves. - Aust. J. Plant Physiol. 9: 121-137.

Fitter, A. H. 1987. An architectural approach to the comparative ecology of plant root systems. - New Phytol. 106: 61-77.
Freschet, G. T. et al. 2011. Global to community scale differences in the prevalence of convergent over divergent leaf trait distributions in plant assemblages. - Global Ecol. Biogeogr 20: 755-765.

Fyllas, N. et al. 2009. Basin-wide variations in foliar properties of Amazonian forest: phylogeny, soils and climate. - Biogeosciences 6: 2677-2708.

Garnier, E. and Navas, M. L. 2012. A trait-based approach to comparative functional plant ecology: concepts, methods and applications for agroecology. - Agron. Sustain. Dev. 32: 365-399.

Garnier, E. et al. 2001. Consistency of species ranking based on functional leaf traits. - New Phytol. 152: 69-83.

Garnier, E. et al. 2004. Plant functional markers capture ecosystem properties. - Ecology 85: 2630-2637.

Grime, J. P. 2001. Plant strategies, vegetation processes and ecosystem properties. -Wiley.

Gross, N. et al. 2009. Linking individual response to biotic interactions with community structure: a trait-based framework. - Funct. Ecol. 23: 1167-1178.

Gross, N. et al. 2013. Uncovering multiscale effects of aridity and biotic interactions on the functional structure of Mediterranean shrublands. - J. Ecol. 101: 637-649.

Holdaway, R. J. and Sparrow, A. D. 2006. Assembly rules operating along a primary riverbed-grassland successional sequence. J. Ecol. 94: 1092-1102.

Holdaway, R. J. et al. 2011. Species- and community-level changes in fine root traits along a 120000 year soil chronosequence in New Zealand. - J. Ecol. 99: 954-963.

IPCC 2001. Climate change 2001: the scientific basis. Contrib. Working Grp I 3rd Assess. Rep. of the Intergovernmental panel on climate change. - Cambridge Univ. Press.

Jackson, R. B. et al. 1997. A global budget for fine root biomass, surface area and nutrient contents. - Proc. Natl Acad. Sci. USA 94: 7362-7366.

Jobbágy, E. G. and Jackson, R. B. 2001. The distribution of soil nutrients with depth: global patterns and the imprint of plants. - Biogeochemistry 53: 51-77.

Jung, V. 2010. Intraspecific variability and trait-based community assembly. - J. Ecol. 98: 1134-1140.

Jung, V. et al. 2014. Intraspecific trait variability mediates the response of subalpine grassland communities to extreme drought events. - J. Ecol. 102: 45-53.

Keddy, P. A. 1992 Assembly and response rules: two goals for predictive community ecology. - J. Veg. Sci. 3: 157-164.

Kichenin, E. et al. 2013. Contrasting effects of plant inter and intraspecific variation on community level trait measures along an environmental gradient. - Funct. Ecol. 27: 1254-1261.

Laliberté, E. et al. 2012. Which plant traits determine abundance under long-term shifts in soil resource availability and grazing intensity? - J. Ecol. 100: 662-677.

Lepš, J. et al. 2011. Community trait response to environment: disentangling species turnover vs intraspecific trait variability effects. - Ecography 34: 856-863.

López-Iglesias, B. et al. 2014. Functional traits predict drought performance and distribution of Mediterranean woody species. - Acta Oecol. 56: 10-18.

MacArthur, R. and Levins, R. 1967. The limiting similarity, convergence and divergence of coexisting species. - Am. Nat. 101: 377-385.

Mayfield, M. M. and Levine, J. M. 2010. Opposing effects of competitive exclusion on the phylogenetic structure of communities. - Ecol. Lett. 13: 1085-1093.

McCormack, L. et al. 2012. Predicting fine root lifespan from plant functional traits in temperate trees. - New Phytol. 195: 823-831.

McGill, B. J. et al. 2006. Rebuilding community ecology from functional traits. - Trends Ecol. Evol. 21: 178-185. 
Oksanen, J. et al. 2007. - The vegan package. - R community ecology package.

Ordoñez, J. C. et al. 2009. A global study of relationships between leaf traits, climate and soil measures of nutrient fertility. Global Ecol. Biogeogr. 18: 137-149.

Pérez-Ramos, I. M. et al. 2012. Evidence for a "plant community economics spectrum" driven by nutrient and water limitations in a Mediterranean rangeland of southern France. - J. Ecol. 100: 1315-1327.

Pérez-Ramos, I. M. et al. 2013. Tradeoffs between functional strategies for resource-use and drought-survival in Mediterranean rangeland species. - Environ. Exp. Bot. 100: 126-136.

Reich, B. et al. 1991. Leaf lifespan as a determinant of leaf structure and function among 23 amazonian tree species. - Oecologia 86: 16-24.

Reich, P. B. et al. 1992. Leaf life-span in relation to leaf, plant and stand characteristics among diverse. - Ecol. Monogr. 62: 365-392.

Reich, P. B. et al. 1998. Photosynthesis and respiration rates depend on leaf and root morphology and nitrogen concentration in nine boreal tree species differing in relative growth rate. - Funct. Ecol. 12: 395-405.

Roche, P. et al. 2004. Congruency analysis of species ranking based on leaf traits: which traits are the more reliable? - Plant Ecol. 174: 37-48.

Ryser, P. 1998. Intra- and interspecific variation in root length, root turnover and the underlying parameters. - In: Lambers, H. et al. (eds), Variation in plant growth. Backhuys Publishers, pp. 441-465.

Sandel, B. et al. 2010. Contrasting trait responses in plant communities to experimental and geographic variation in precipitation. - New Phytol. 188: 565-75.

Shipley, B. et al. 2006. From plant traits to plant communities: a statistical mechanistic approach to biodiversity. - Science 314: 812-814.

Supplementary material (available online as Appendix oik01875 at <www.oikosjournal.org/appendix/oik-01875>). Appendix 1-5.
Shipley, B. 2010. From plant traits to vegetation structure: chance and selection in the assembly of ecological communities. - Cambridge Univ. Press.

Siefert, A. 2012. Incorporating intraspecific variation in tests of trait-based community assembly. - Oecologia 170: 767-775.

Silva, J. S. and Rego, F. C. 2003. Root distribution of a Mediterranean shrubland in Portugal. - Plant Soil 255: 529-540.

Silva, J. S. and Rego, F. C. 2004 . Root to shoot relationships in Mediterranean woody plants from central Portugal. - Biologia 59: 1-7.

Sparks, D. L. 1996. Methods of soil analysis. Part 3. Chemical method. - Soil Sci. Soc. Am. Book Series 5, Madison, WI.

Spasojevic, M. J. and Suding, K. N. 2012. Inferring community assembly mechanisms from functional diversity patterns: the importance of multiple assembly processes. - J. Ecol. 100: 652-661.

Stubbs, W. J. and Wilson, J. B. 2004. Evidence for limiting similarity in a sand dune community. - J. Ecol. 92: 557-567.

Suding, K. N. et al. 2005. Functional- and abundance-based mechanisms explain diversity loss due to $\mathrm{N}$ fertilization. - Proc. Natl Acad. Sci. USA 102: 4387-4392.

Terradas, J. 2001. Ecología de la Vegetación. De la Ecofisiología de las Plantas a la Dinámica de Comunidades y Paisajes. - Omega, Barcelona.

Violle, C. et al. 2007. Let the concept of trait be functional! Oikos 116: 882-892.

Weiher, E. and Keddy, P. 1999. Ecological assembly rules: perspectives, advances, retreats. - Cambridge Univ. Press.

Weiher, E. et al. 2011. Advances, challenges and a developing synthesis of ecological community assembly theory. - Phil. Trans. R. Soc. B 366: 2403-2413.

Wright, I. J. et al. 2004. The worldwide leaf economics spectrum. - Nature 428: 821-827. 